\title{
Assimilation of TTF and UTAUT for Mobile Banking Usage
}

\author{
Sayyed Khawar Abbas ${ }^{1}$, Hafiz Ali Hassan ${ }^{1}$, Seharish Iftikhar ${ }^{1}$, Ali Waris ${ }^{2}$ \\ ${ }^{1}$ Hailey College of Commerce, University of the Punjab, Pakistan \\ ${ }^{2}$ University of Lahore, Chenab Campus, Gujrat, Pakistan
}

\begin{abstract}
Introduction of mobile banking has enlightened the new ways of business penetration for traditional banks. Over the last two decades, availability of internet and data services massively increased mobile usage which boosted the demand for mobile banking due to its ubiquity and immediacy features. This paper seeks to explore the user perception against mobile banking adoption with technology perspective. The assimilation of "TTF" tasktechnology fit and "UTAUT" unified theory of acceptance and usage of technology projected a mobile banking adoption model. It further proposed that task-technology fit and customization of technology influences user adoption. This Study came with diversified results of developing country like Pakistan.
\end{abstract}

Keywords —Mobile banking, TTF, UTAUT, User adoption.

\section{INTRODUCTION}

Mobile banking is also known as electronic banking or SMS banking. Over the last two decades, it has become a pivotal phenomenon in the banking industry. The European company named pay box supported financially by Deutsche bankstarted first ever mobile banking services back in 1999. According to Zhou, Lu, \& Wang(2010), mobile banking can also be referred to phone banking where mobile phones and personal digital assistants (PDA's) are being used to assess banking services via a wireless application protocol (WAP). Luarn \& Lin(2005), stated by using mobile banking consumer can determine information inquiry, account management, money transfers, bill payments and other banking operations. It is free from spatial constraints as compared to Internet-basedbanking operations where the consumer can acquire real-time account anywhere and able to perform banking operations. Mobile banking has helped traditional banks to enhance their service quality, cost reduction and improved operations(Abbas, Hassan, Asif, Junaid, \& Zainab, 2018).

Now a day, the collaboration of telecommunication service providers with banking sector has opened new doors for sparking future of banking industry. Mobile banking widely adopted in developed countries and developing countries are also following the trend with the passage of time (Ahmed, Ammar, \& ALI, 2016). This service is also getting massive acceptance in Pakistani market especially inlowincome households. The massive penetration of mobile usage in 2012 reached to 120.5 million subscribers. According to Pakistan Telecommunication Authority(2014), the population of mobile users has reached to 139.20 million, whereas only $12 \%$ population is engaged in mobile banking (Abbas, Hassan, Asif, Junaid, \& Zainab, 2018).

According toZhou, Lu, \& Wang(2010), various studies have enriched the literature regarding mobile user adoption based on numerous factors including perceived usefulness, relative advantage, compatibility, perceived ease of use and perceptions about technology. He further argued that by exploring user's understandingof technology acceptance is not enough. Junglas et al. (2008), contended advancement in technology acknowledged by users does not lead to adoption if the technology is not fit with their needs, requirements and not able to improve their performance. Similarly, Goodhue \& Thompson (1995), argued individuals will tend to adopt such technology which is in line with their requirements and developing their routine life.

\section{Literature Review}

According to Vaidya (2011), mobile banking refers to the service provided by banks and other financial institutions which allows the customer to perform monetary transactions remotely with handheld devices such as mobile, smartphones, and tablets. An internet software usually called "app" is used for these services. Mobile banking is widely accepted due to its mobility, availability, lows cost and ubiquity (Junglas, Abraham, \& Watson, 2008).

The use of information technology in everyday business is enormous these days. The inclusion of mobile banking has enriched the literature of information technology for a company not only in academic but also in practical life as 
well(Oliveira, Faria, Thomas, \& Popovič, 2014). Many theories and research models including (TAM) technology acceptance model (Davis, 1989), (IDT) innovation diffusion theory (Rogers, 1995), (TTF) task-technology fit (Goodhue \& Thompson, 1995), and (UTAUT) Unified theory of acceptance and usage of technology (Venkatesh, Morris, Davis, \& Davis, 2003) have been applied to explore the intentions for mobile banking adoption. Similarly, Zhou, Lu, \& Wang(2010), presented mobile banking adoption model by integrating TTF and UTAUT models. They demonstrated mobile banking adoption is not only affected by perception towards technology but also customization of technology in fulfilling routine activities. Furthermore, another study by (Oliveira, Faria, Thomas, \& Popovič, 2014) showed task-technology fit, technology characteristics, and initial trust and performance expectancy affect mobile banking adoption with a sample of 194 valid responses.

The task-technology fit (TTF) model suggests the adoption of new technology is dependent on the characteristics which fulfill the desired routine tasks. Hence, the technology will only be adopted if it can assist customer needs (Goodhue \& Thompson, 1995). The model consists of four characteristics including task-technology, task characteristics, technology fit and further use. The first two elements are responsible for technology fit which further leads to technology adoption. TTF model is widely recognized and has used in many types of research. Dishaw $\&$ Strong(1999), conducted an investigationon exploring the relationship between software usage and performance by integrating TTF and (TAM) technology acceptance models. Likewise, Lee et al. (2007), further explored the factors which influence the mobile commerce adoption by using modified TTF model. Furthermore, mobile banking adoption is also examined by (Zhou, Lu, \& Wang, 2010) with the integration of TTF and UTAUT models.

A unified theory of acceptance and usage of technology (UTAUT) model was an extension of Technology acceptance model (TAM) (Davis, 1989). The UTAUT model was a public improvement of TAM. The Unified theory is aimed to find out the user intention towards technology adoption and their subsequent behavior (Oliveira, Faria, Thomas, \& Popovič, 2014). It suggests three main antecedents including social influence, effort expectancy and performance expectancy.Age and gender mainly influence the impact of these factors on behavioral intention. The unified theory model has gained popularity and used in many research settings to examine the behavioral plan of subsequent technology adoption (Hong, Thong, Chasalow, \& Dhillon, 2011). A research study performed by (Luo, Li, Zhang, \& Shim, 2010)analyzed the risk, trust, self-efficiency,and performance expectancy impact on banking adoption and concluded, these factors have a significant impact on mobile banking services acceptance.

\section{METHODOLOGY}

A developed questionnaire adapted from(Zhou, Lu, \& Wang, 2010). Moreover, to analyze the trustworthiness of data reliability and confirmatory factor analysis has been run to the data. Reliability test shows all constructs having Cronbach's Alpha around 0.70 which means sample size is adequate to run the test. The population is mobile banking users and non-users of Pakistan, so the nonprobability technique of snowball sampling is used to collect data. OLS is being utilized for the analysis purposes as all constructs are calculated at 5 pointsLikert scale. Study setting is noncontrived. This Study is a cross-sectional study.

Following model has been constructed upon literature mentioned above.

$$
\begin{gathered}
U A=\alpha+\beta 1 T T F+\beta 2 P E+\beta 3 E E+\beta 4 S I+\beta 5 F C \\
+e
\end{gathered}
$$

Where:

$\mathrm{UA}=$ User Adoption of the individuals

TTF $=$ Task-Technology Fit

$\mathrm{PE}=$ Performance Expectancy

$\mathrm{EE}=$ Effort Expectancy

SI= Social Influence upon individuals

$\mathrm{FC}=$ Facilitating Conditions available

The model proposes that UA got affected by TTF, PE, EE, SI,and FC. To conduct the analysis initially, 385 sample size was suggested. 750 questionnaire distributed. Whereas, only 611 responses found useful. Sample space of the study was Cities of Lahore, Islamabad,and Karachi. These three cities represent the most of Pakistan Population. 


\section{RESULTS}

Following findings were found by analyzing the data collected.

\begin{tabular}{|c|c|c|c|}
\hline \multicolumn{4}{|c|}{ Variables in the equation } \\
\hline & B & S.E. & Sig. \\
\hline TTF & $.221 * *$ & .066 & .031 \\
\hline PE & $.019 * *$ & .013 & .025 \\
\hline EE & $.021 * *$ & 016 & .039 \\
\hline SI & $.311 * * *$ & .054 & .001 \\
\hline $\mathrm{FC}$ & $.112 * *$ & .021 & .017 \\
\hline Constant & 167 & .121 & .268 \\
\hline
\end{tabular}

It could observe that TTF $(+.221)$, PE (+.019), EE (+.021) and $\mathrm{FC}(+.112)$ are significant at $5 \%$ level of significance in the model and SI $(+.331)$ is significant at $1 \%$ level of significance. Model is fit and R Square shows TTF, PE, EE, SI, and FC explains to UA 57\%. All variables are having a positive relationship with UA. As standard errors are below the betas, it also shows that data is sound and analysis run upon data will be useful. So the model can be explained as

$$
\begin{aligned}
U A=0.167+ & 0.221 T T F+.019 P E+.021 E E \\
& +0.331 S I+0.112 F C
\end{aligned}
$$

\section{CONCLUSION}

Concluding this study, it can see that Social influence most infusing factor. It can also infer from a country background. Developing countries Like Pakistan where poverty headcount ratio @ \$1.90 a day is most influential by income distribution level (Abbas, Hassan, Asif, \& Zainab, 2018) and where behavioral, cognitive and emotional factors strongly effects the consumers approach (Abbas, Hassan, Hashmi, \& Waqar, 2018)social influence has proven powerful factor to influence user adoption. Individuals usually follow the pros and cons of things from others experiences. Task-Technology fit also having a positive relationship with user adoption. It means that emerging technology proves as fit to task completion then people will move towards the adoption. It contains two aspects of technology and task. Both orientations matters to users here. Performance expectancy is also having a positive strong relationship with user adoption. It will elaborate that if performance expectancy remains full filled but adoption, then adoption will enhance. Effort expectancy also illustrates this relationship with user adoption. It shows that if people get the effort according to expectancy, this will make their mind clear about the mobile banking services, then they could move towards the mobile banking. Another emphasizing factor is facilitating conditions. Facilitating conditions having a diverse range and these strengthen the mobile banking. As Remodeling of risk management practices required in Pakistan (Abbas, Haider, Zainab, Hassan, \& Fazal, 2018), this could be proved to facilitate conditions too. It could determine a substantial factorto enhance the base of mobile banking users.

Future researchers could explore the effect ofTTF, UTAUT, and ITM (Initial trust model) to mobile banking adoption. This Study is having implications for providers, users and regularity authorize.

\section{REFERENCES}

[1] Abbas, S. K., Hassan, H. A., Asif, J., \& Zainab, F. (2018). HOW INCOME LEVEL DISTRIBUTION RESPONDS TO POVERTY: EMPIRICAL EVIDENCE FROM PAKISTAN. Global Scientific Journals, 6(3), 131-142.

[2] Abbas, S. K., Hassan, H. A., Asif, J., Junaid, H. M., \& Zainab, F. (2018). What are the key determinants of mobile banking Adoption in Pakistan? International Journal of Scientific \& Engineering Research, 9(2), 841-848.

[3] Abbas, S. K., Hassan, H. A., Hashmi, Z. M., \& Waqar, N. (2018). HOW COGNITIVE, EMOTIONAL AND BEHAVIORAL DETERMINANTS AFFECT CONSUMER CREDIT APPROACH? Global Scientific Journals, 6(3), 164-171.

[4] Abbas, S., Haider, S., Zainab, F., Hassan, H., \& Fazal, A. (2018). Why remodeling of risk management Practices in banking is required? Evidence from Pakistan. International Journal of Scientific \& Engineering Research, 9(2), 686-691.

[5] Ahmed, E. M., Ammar, A., \& ALI, A. E. (2016). SUDANESE MICROFINANCE SERVICES PROVIDERS DRIVERS FOR INTENTION TO ADOPT MOBILE BANKING. The Journal of Internet Banking and Commerce, 21(3), 1-12. 
[6] Davis, F. D. (1989). Perceived usefulness, perceived ease of use, and user acceptance of information technology. MIS Quarterly, 319-340.

[7] Dishaw, M. T., \& Strong, D. M. (1999). Extending the technology acceptance model with task-technology fit constructs. Information \& Management, 36(1), 9-21.

[8] Goodhue, D. L., \& Thompson, R. L. (1995). Tasktechnology fit and individual performance. MIS Quarterly, 213-236.

[9] Hong, W., Thong, J. Y., Chasalow, L. C., \& Dhillon, G. (2011). User acceptance of agile information systems: A model and empirical test. Journal of Management Information Systems, 28(1), 235-272.

[10] Junglas, I., Abraham, C., \& Watson, R. T. (2008). Task-technology fit for mobile locatable information systems. Decision Support Systems, 45(4), 1046-1057.

[11]Lee, C. C., Cheng, H. K., \&vCheng, H. H. (2007). An empirical study of mobile commerce in insurance industry: Task-technology fit and individual differences.Decision Support Systems, 43(1), 95-110.

[12]Luarn, P., \& Lin, H. H. (2005). Toward an understanding of the behavioral intention to use mobile banking. Computers in Human Behavior, 21(6), 873-891.

[13]Luo, X., Li, H., Zhang, J., \& Shim, J. P. (2010). Examining multi-dimensional trust and multi-faceted risk in initial acceptance of emerging technologies: An empirical study of mobile banking services.Decision support systems, 49(2), 222-234.

[14] Oliveira, T., Faria, M., Thomas, M. A., \& Popovič, A. (2014). Extending the understanding of mobile banking adoption: When UTAUT meets TTF and ITM. International Journal of Information Management, 34(5), 689-703.

[15]PTA. (2014). Pakistan Telecommunication Authority Govt Agency.

[16] Rogers. (1995). Diffusion of innovations (3 ed.). New York: New York Free Press.

[17] Vaidya, S. R. (2011). "Emerging Trends on Functional Utilization of Mobile Banking in Developed Markets in Next 3-4 Years". International Review of Business Research Papers, 7(1), 301 - 312.

[18] Venkatesh, V., Morris, M. G., Davis, G. B., \& Davis, F. D. (2003). User acceptance of information technology: Toward a unified view.MIS Quarterly, 425-478.

[19]Zhou, T., Lu, Y., \& Wang, B. (2010). Integrating TTF and UTAUT to explain mobile banking user adoption. Computers in Human Behavior, 26(4), 760-767. 